\title{
Territorializações urbanas como práticas de resistência
}

\section{Urban territorialization as practices of resistance}

\author{
Alessandro Dozena \\ sandozena@ufrnet.br \\ Universidade Federal do Rio Grande do Norte
}

Resumo: O presente artigo objetiva discutir a temática das territorializações urbanas a partir das práticas de "resistência territorial" efetivadas por outras racionalidades, que se dão por meio de usos territoriais não vislumbrados pela racionalidade hegemônica. Assim, a noção de contrafinalidade, elaborada por Jean Paul Sartre, permitiu a reflexão sobre as territorializações urbanas contendo um potencial de ação e para a ação, fundamentado na corporeidade, espontaneidade, criatividade, solidariedade e em experiências espaciais potencializadoras de um cotidiano menos esquemático e repetitivo. Considerando-se a contrafinalidade como aquilo que nem sempre faz parte de um sistema de objetivos claros e materiais, buscou-se uma contribuição no sentido do diálogo com alguns autores, destacadamente com a noção de horizontalidades trabalhada por Milton Santos.

Palavras-chave: Territorialização. Contrafinalidade. Corporeidade.

Abstract: This paper discusses the topic of urban territorialization, based on practices of "territorial resistance" executed by other rationalities, which occur through territorial uses not envisioned by the hegemonic rationality. The Sartre's notion of counter-finality has enabled us to reflect about territorialization containing a potential to action and of action, grounded in corporeality, spontaneity, creativity, solidarity and spatial experiences of one less schematic and repetitive daily-life. Considering the notion of counter-finality as something which is not always part of a system of clear and materials objectives, we tried finding a contribution regarding dialogue with different authors, especially with the notion of horizontality by Milton Santos and the notion of counter-finality by Jean Paul Sartre.

Keywords: Territorialization. Counter-finality. Corporeality.

Resumen: Este artículo aborda el tema de las territorializaciones urbanas a partir de las prácticas de la "resistencia territorial", realizadas por otras racionalidades, que se dan por medio de los usos territoriales no vislumbrados por la racionalidad hegemonica. De este modo, la noción de contrafinalidad elaborada por Jean Paul Sartre permitió la reflexión sobre las territorializaciones urbanas que contienen un potencial de acción y para la acción, basado en la corporeidad, espontaneidad, solidaridad y en experiencias espaciales de un cotidiano, menos esquemático y repetitivo. Teniendo en cuenta la contrafinalidad como aquello que ni siempre hace parte de un sistema de objetivos claros y materiales, se buscó una contribución con el sentido del dialogo con algunos autores, destacándose la noción de horizontalidades trabajada por Milton Santos.

Palabras clave: Territorialización. Contrafinalidad. Corporeidad. 


\section{INTRODUÇÃO}

Os processos de territorializações urbanas são históricos, manifestando-se densos de particularizações temporais para cada época e delineando-se formas preponderantes de reprodução da sociedade, resultado de múltiplos processos econômicos, políticos e culturais. Nessas articulações espaciais, revela-se comumente uma lógica territorial e um sentido histórico dinâmico relacionado a experiências espaciais potencializadoras de um cotidiano menos esquemático e repetitivo.

Nesse artigo, propomos abordar as territorializações urbanas como práticas de resistência capazes de tornar a vida menos rotineira, mecanizada e administrada. Essa premissa dialoga com a concepção de contrafinalidade trabalhada por Jean Paul Sartre (2002) e de outras racionalidades, trabalhada por Milton Santos (2002). Com esse propósito, discutiremos a temática das territorializações urbanas a partir das práticas de "resistência territorial" efetivadas por outras racionalidades, que se dão por meio de usos territoriais não vislumbrados pela racionalidade hegemônica.

Na primeira parte, intitulada "Práticas de contrafinalidade como resistência territorial", as territorializações urbanas serão abordadas considerando-se o fato de que as práticas, discursos e representações podem guardar um caráter de contrafinalidade por nem sempre ter finalidade, incorporando um caráter lúdico e transgressor que não pertence à lógica produtivista, mas sim à da imaginação e da sensibilidade. A partir do estabelecimento das territorializações urbanas, as estruturas consolidadas de poder no espaço urbano podem ser desafiadas pelas práticas, representações e discursos de contrafinalidade.

Na segunda parte, intitulada "O papel da corporeidade na conformação das territorializações urbanas", destacamos o fato de que a dimensão da corporeidade revelase enquanto oportunidade de criação de redes de convivência e de solidariedade, traduzindo-se como o núcleo primeiro da sociabilidade. A corporeidade contribui para um primeiro reconhecimento que se dá entre as pessoas, uma primeira forma de apresentação fundamental para a interação que acontece com outros corpos; no ato da socialização e da conformação de territorializações urbanas.

\section{PRÁTICAS DE CONTRAFINALIDADE COMO “RESISTÊNCIA TERRITORIAL"}

A temática das territorializações urbanas nos permite uma interessante reflexão acerca das práticas e dos discursos sociais enquanto modos de "resistência territorial", na medida em que tais práticas e discursos evidenciam uma trama de localizações de objetos geográficos inseridos em processos sociais específicos, que podem ser desvelados a partir de um "olhar" atento do pesquisador.

Partimos do referencial teórico posto por Milton Santos (2002), ao afirmar a existência de contrarracionalidades pautadas em narrativas, discursos e práticas socioespaciais que realizam uma contrapartida às narrativas midiáticas e ao mundo da velocidade. 
Na literatura acerca das manifestações culturais atreladas a esses usos territoriais não vislumbrados pela racionalidade hegemônica, pouco se encontra relacionado às manifestações que evidenciam um sentido que nem sempre tem o "industrialismo" das culturas como o fim, mas que evidenciam outras racionalidades; outras "razões emocionantes".

De certo modo, tais racionalidades reivindicam o direito a uma "democracia festiva", o direito à visibilidade e à expressão do modo de viver de agrupamentos sociais que produzem uma arte contemporânea e popular, que não se trata meramente de uma arte folclórica.

Por outro lado, a noção de territorialização nos possibilita o entendimento das manifestações da cultura popular apresentando um potencial de ação e para a ação, uma condição para a produção de novas consciências com um caráter lúdico e transgressor, consciências que não pertencem à lógica produtivista, mas à da imaginação e sensibilidade.

Torna-se importante evitar a caracterização das manifestações da cultura popular como manifestações de pureza. Tal noção de pureza está muito relacionada a uma representação/invenção específica acerca de parcela da população brasileira, especificamente aquela que representa as classes socioeconômicas mais desfavorecidas. Tal acionamento da noção de pureza encontra-se muito presente no ideário propagado pelos meios de comunicação, além de já ter sido atrelado ao imaginário sobre o homem do campo, sobre o homem simples na metrópole, entre outros imaginários.

Nas décadas recentes, temos percebido que o agente de origem popular não mais quer ser retratado a partir dos pressupostos e opiniões advindos das concepções elaboradas pela classe média, além de não mais se enquadrar na classificação do operariado alienado abordado pela perspectiva marxista. Os agrupamentos sociais empobrecidos passam a acionar (ou intencionam acionar) o mundo com as suas próprias significações.

A noção de contrafinalidade aqui abordada tem seu fundamento na perspectiva elaborada por Sartre (2002), ao tratar das situações de escassez, em que haveria um direcionamento do coletivo contra as buscas individuais, de modo a se impedir a ruína de todos.

Dialogando com Sartre, Milton Santos propõe a noção de horizontalidades como sendo tanto a finalidade imposta de fora quanto a contrafinalidade localmente gerada. Para Santos (2002), "os pobres abrem um debate novo, às vezes silencioso, às vezes ruidoso, com as populações e as coisas já presentes, encontrando novos usos e finalidades para objetos e técnicas e também novas articulações práticas e novas normas na vida social" (p. 326).

De certo modo, a relação da classe média com as manifestações populares geralmente se dá de modo romantizado, na medida em que aquela apregoa ou pré-estabelece um caráter de essência para as manifestações populares. Entretanto, a existência precede a essência (SARTRE, 2002) e de certo modo, torna possível avançar na proposta da operação da vida sobrepondo-se à representação dela, ou seja, na consideração de que a esperança existe como parte da ação na medida em que o campo dos possíveis pode ser construído a partir do real e de suas virtualidades. 
Nas cidades, a espontaneidade e a criatividade podem atuar como resposta àqueles que as imaginam desprovidas da possibilidade do encontro e da experiência urbana nos seus aspectos de partilha e solidariedade, ainda que essa sociabilidade coexista com os conflitos e as contradições inerentes às relações sociais.

A cultura popular evidencia maneiras de se operar simbolicamente com a vida, e não representa somente algo que já existiu, como um cotidiano esquemático e repetitivo (LEFEBVRE, 1991), mas resiste a algumas ações do mercado, sobretudo as que intencionam divulgar uma representação inventada de cultura brasileira e de Brasil.

Ao considerarmos o cotidiano como o lugar da descoberta e da vida (SANTOS, 2002), torna-se impreciso tratar a cultura popular como folclórica, tampouco considerar a cidade somente como sendo o local em que os atos humanos se deixam levar por uma rotina mecânica, fixada na competição e nas ações repetitivas.

A aceitação dos argumentos que dizem respeito à tendência de uniformização cultural no atual período histórico não implica adesão à tese de que não é mais possível falar em resistência cultural. Ao longo da trajetória histórica do pensamento nas ciências humanas, a noção de resistência cultural ou de contra-hegemonia foi trabalhada por distintos autores, conforme o campo disciplinar que a equacionou. Assim sendo, uma reflexão profunda sobre essa temática pode ser encontrada nos autores da chamada Escola de Frankfurt, notadamente nas obras de Adorno e Horkheimer.

Segundo Adorno (2002), o advento da Indústria Cultural fez com que a sua influência passasse a ser exercida em praticamente todos os âmbitos sociais, não só assimilando as resistências culturais em diferentes pontos do mundo como também acionando as ações políticas intencionadas à geração de "novos" gostos e padrões de consumo. Vale lembrar que o conceito de Indústria Cultural foi cunhado a partir da análise do rádio nos Estados Unidos.

Raymond Williams (1980) afirma que a hegemonia constitui um corpo de práticas e expectativas em relação à totalidade da vida, em que os grupos sociais dominantes renovam, recriam, defendem e modificam a hegemonia exercida por eles em uma existência recíproca com a contra-hegemonia. Essa existência recíproca envolve uma "anti-imagem", situação em que a ação de uma é diretamente proporcional à ação da outra.

Do mesmo modo, Michel Foucault (1979) examina a concepção de contra-discursos, evidenciando a relevância dos "saberes sujeitados" locais, das micro-histórias e dos registros cotidianos banais capazes de fortalecer os sujeitos na coletividade, normalmente depreciados diante da prevalência das narrativas oficiais legitimadoras do poder instituído.

Em uma perspectiva geográfica, Rogério Haesbaert (2006) trata da "configuração de contra-espaços dentro das ordens sociais majoritárias", tanto na escala das relações cotidianas quanto nas escalas mais amplas. Para ele, é "neste jogo de contraposições que pode ser divisado e incentivado um novo arranjo espacial, capitaneado por uma base democrática que permita o confronto de identidades, com o florescimento permanente de uma diversidade libertadora" (HAESBAERT, 2006, p. 15). 
Seguindo essa formulação, acreditamos que algumas territorializações urbanas cada vez mais possibilitam a configuração de contra-espaços dentro das ordens sociais majoritárias; desafiando o poder estabelecido por intermédio da objetivação das territorializações.

Nessa dinâmica de contraposições e confrontos, as práticas sociais e discursos podem surgir como uma contrafinalidade, evidência da efetividade de "outras formas de racionalidade, racionalidades paralelas, divergentes e convergentes ao mesmo tempo (SANTOS, 2002, p. 309).

Mas também, em muitas ocasiões, alguns comportamentos que não se enquadram nos padrões da racionalidade são férteis para as criações artísticas inovadoras. Atentamos para esse fato a fim de se evitar uma visão dual ao se trabalhar dialeticamente com a noção de contrafinalidade. Consideramos que o que é racional pode momentaneamente se tornar irracional, ou seja, pode haver em alguns casos a coexistência dialética entre a racionalidade e a irracionalidade, ao mesmo tempo, não havendo uma racionalidade paralela em virtude de uma estar entranhada na outra.

Embora devamos considerar que nem sempre as práticas e discursos sociais se mantenham como contrafinalidade irredutível à racionalidade econômica (sobretudo se considerarmos a dinâmica das manifestações culturais voltadas ao espetáculo, em grande parte dominadas pelos interesses lucrativos), acreditamos que as práticas e discursos sociais têm o potencial de apontar caminhos novos e insuspeitos ao pensamento e à ação popular, estimulando o sonho de mudança, induzindo e auxiliando na conscientização crítica para a ação transformadora. Tais práticas e discursos podem ser considerados como uma finalidade sem fim, nem sempre utilitária, mas resgatadora da condição humana e possibilitadora de sentimentos de esperança. As territorializações urbanas podem consistir em locais de sociabilidade onde se expressam experiências não remuneradas, fundamentadas no encontro comum que ali se dá e que torna esses lugares um ambiente comum a todos.

Nesses lugares, nem sempre as práticas sociais são regidas por normas, regras ou leis, configurando-se em genoespaços, segundo a formulação de Gomes (2002), em uma contraposição que coexiste com os nomoespaços, a base fundadora de uma sociedade de contrato, uma "condição necessária para que se configure a ideia de um pacto social do tipo contratual" (p. 40).

Vale observar que em muitos posicionamentos assumidos a respeito das manifestações culturais brasileiras, emerge a proposição da resistência cultural, muitas vezes desconsiderando o fato de que a principal experiência social ainda é eminentemente capitalista, embora muitos apregoem a possibilidade da emergência de outro modo de produção. Poder-se-ia lembrar-se da irônica frase de Fredric Jameson, de que "a melhor e a pior coisa criada pela sociedade foi o Capitalismo". Assim sendo, a crítica ao modo de produção capitalista está na base dos posicionamentos e discursos que não conseguem vislumbrar efetivamente uma proposta de conteúdo político-ideológico alternativa à vigente. 
Nas leituras realizadas, constatamos que são comuns as confusões entre o que é o capitalismo e o que é o comércio. Em grande parte, o equívoco ocorre pelo esquecimento de que o capitalismo é um modo de produção configurado a partir do século XVI, ao contrário do comércio, que existe há muito mais tempo. Esquece-se ainda de que não é porque algo é comercializável que ele se transforma em algo capitalista. Igualmente, é comum a ideia de que tudo o que passa pelo circuito comercial e envolve dinheiro acaba sendo moralmente condenável e/ou condenado.

Nesse quadro, alguns questionamentos adquirem importância: Em qual plano se coloca a resistência cultural na atualidade? A resistência sempre tem uma característica progressista no sentido do benefício social, a partir da força instaurada pelo e no lugar? A resistência também não poderia ser percebida como um ato reacionário no sentido da manutenção das forças hegemônicas?

O debate sobre a caracterização da resistência tece equacionamentos interessantes para a argumentação em curso nesse artigo. Sem dúvida alguma, as transformações ocorridas nas dinâmicas e processos sociais nas últimas décadas ocasionaram profundas mudanças na abordagem das categorias e conceitos das Ciências Humanas. Assim, novos valores e práticas se instituíram, atribuindo ao mundo novas sociabilidades que as Ciências Humanas cada vez mais têm buscado compreender.

Uma argumentação fértil para esse tema emerge no entendimento que estabelece a relação entre resistência e contrafinalidade. Nesse entendimento, busca-se a libertação das limitações postas pelos critérios de resistência oriundos de dinâmicas e processos sociais já superados, pois sendo parte dos processos sociais, a resistência cultural se modificou historicamente e ainda continua se modificando. Porém, sua manifestação concreta ainda ocorre guiada pelas determinações gerais impostas pelo ideário econômico dominante em cada lugar.

Nessa perspectiva, o imperativo da resistência impõe-se atualmente pela variedade de gêneros de vida existentes (La Blache), pautada pelos também diversos "habitus" (Bourdieu), requalificados continuamente enquanto práticas e discursos sociais que expõe as singularidades locais diante de um gênero de vida propagado pelo ideário econômico predominante.

Dos gêneros de vida, alguns arranjos específicos podem ser identificados em sua relação com as territorializações, arranjos que são particularizados na medida em que as influências e condicionamentos oriundos das características do meio (construído, natural e relacional) imprimem tonalidades locais às relações próprias de um dado agrupamento social em cada lugar específico. Tais arranjos se consolidam na busca pela salvaguarda do "habitus", situação subjetiva que marca um posicionamento em relação às experiências existenciais, além de circunscrever uma realidade demarcada temporal e espacialmente.

Assim sendo, a resistência se afirma como um elemento particularizador, uma mediação que, quando aplicada sobre o próprio processo singular da formação existencial de cada indivíduo (visto que a resistência se referencia na existência), contribui para a produção de territorializações. Nesse ponto específico, Milton Santos considera que o mundo do cotidiano é também o da produção ilimitada de outras racionalidades, tão 
diversas quanto as áreas consideradas, pois abrigam todas as modalidades da existência (SANTOS, 2008).

Por outro lado, é interessante mencionar que Karl Marx (1983) considerava a arte como algo não pertencente à superestrutura (ao contrário da política e da economia). Para ele, a arte só se tornaria "alienada" caso fosse englobada enquanto mercadoria. Por isso, Marx destacava a importância da arte na objetivação do ser humano diante da necessidade de realçar a sua sensibilidade. Cabe lembrar que a ótica do autor foi formulada no século XIX, em um momento em que muitos cenários artísticos ainda não se encontravam consolidados e a cultura de massas (Adorno) ainda não se configurava plenamente. Interessantemente, como já comentado, a abordagem da cultura de massas foi tomada por um forte pessimismo, na medida em que foi impregnada pela crença na tese da homogeneização cultural.

Em praticamente todos os países, os valores de uma cultura mundial romperam os nexos de identidades circunscritas a escalas locais, descaracterizando implacavelmente os gêneros de vida em nome de um poder hegemônico que se vale de estratégias logisticamente planejadas e com interesses altamente lucrativos.

À luz de tais pressupostos, acreditamos não mais ser possível enfocar qualquer estudo no argumento do tradicional como sinônimo de atraso e do moderno como de avanço ou progresso. Em outros termos, trata-se de buscar no "plano das ideias", alternativas à nova conjuntura "requalificadora" dos conceitos e das categorias de análise.

Deixando-se de lado os posicionamentos dualistas, cabe assinalar que o conjunto da obra de Milton Santos fornece importantes fundamentos teórico-metodológicos para a reflexão a respeito desse mosaico de dinâmicas presentes na vida social contemporânea. Trazendo a reflexão para o presente artigo, o papel de contrafinalidade representado pelas práticas sociais, discursos e representações; aparece como a expressão candente do processo de resistência à tendência de desagregação da sociabilidade e dos gêneros de vida a ele vinculado.

A noção de contrafinalidade aqui proposta, situa-se dentro do processo social, ou seja, ainda que os indivíduos não façam parte do poder hegemônico, também não se encontram totalmente excluídos. Nesta perspectiva, Milton Santos (2002) argumenta que determinados grupos, a exemplo dos migrantes, não se encontram verdadeiramente excluídos, mas, apresentam práticas de racionalidades paralelas (embora tidas comumente como irracionais) que se dissolvem no processo social: dialético, convergente e divergente ao mesmo tempo.

Acreditamos que quando Milton Santos trata da contrarracionalidade está se referindo a outra razão, uma "razão emocionante" ao invés de uma "razão racionalizante". Em geral, tem-se o hábito de se acreditar que a emoção é irracional, sendo que ela não deveria ser considerada como um parâmetro de racionalidade. $\mathrm{O}$ tratamento que costumeiramente é dado aos loucos é o de seres irracionais, que merecem permanecer em estado de encarcerados; mesmo sabendo que isso lhes produzirá mais loucura. Nessa articulação, é possível visualizar um indivíduo "outsider", que em qualquer situação em que se encontre, poderá se opor a uma carreira ou a um procedimento produtivista. 
Ainda num plano genérico de argumentação, pode-se afirmar que muitos indivíduos desenvolvem estratégias de vida que atuam na direção de, e ao mesmo tempo contra o que está estabelecido, buscando uma liberdade diretamente atrelada ao contexto em que cada grupo social se insere. Há de se considerar o fato de que as manifestações culturais são dinâmicas e estão sendo cotidianamente reinventadas, embora não necessariamente arruinadas pela sua transformação em espetáculo (como se houvesse uma perda inexorável diante dos processos de transformação cultural).

No período histórico atual, há cada vez mais a apropriação do sentido da mercadoria e de tudo o que ela vai conseguindo tocar. No entanto, nem todas as instâncias da vida social e simbólica se transformam em mercadorias, embora haja uma forte tendência dominante para tal. Antagonicamente, existem relações de troca que não são comerciais, ainda que toda prática comercial seja uma troca que se utiliza da mercadoria. Da mesma forma, pode-se considerar que nem tudo é global, mesmo diante do processo de globalização que atua reforçando os localismos e os regionalismos em uma dinâmica cultural processual.

Para fundamentar ainda mais esta argumentação, cabe bem estabelecer o suporte empírico a partir do lugar, pois é a partir dele que se dá a "consciência do mundo". Tal relação ocorre ao mesmo tempo em que cada lugar se encontra "imerso numa comunhão com o mundo" e se torna diferente dos demais visto que "a uma maior globalidade, corresponde uma maior individualidade" (SANTOS, 2002, p.314) ${ }^{1}$.

A diversificação dos lugares expressa a desigual presença de processos sociais em cada localidade, exigindo-se a consideração das distintas práticas de consciência e de criatividade. Essa possibilidade histórica dada pela tomada de consciência solicita uma abordagem geográfica do cotidiano, já que é na prática cotidiana que surgem possibilidades de usos territoriais não vislumbrados pela racionalidade hegemônica. Nesse sentido, as territorializações urbanas apontam para um projeto civilizacional cunhado a partir dos lugares:

Globais, os lugares ganham um quinhão (maior ou menor) da "racionalidade" do "mundo". Mas esta se propaga de modo heterogêneo, isto é, deixando coexistir outras racionalidades, isto é, contrarracionalidades, a que, equivocadamente e do ponto de vista da racionalidade dominante, se chamam "irracionalidades". Mas a conformidade com a razão hegemônica é limitada, enquanto a produção plural de "irracionalidades" é ilimitada. É somente a partir de tais irracionalidades é possível a ampliação da consciência (SANTOS, 2008, p.114).

Nesse ponto da argumentação, pode-se considerar a existência de um “tempo dos lentos", com um forte componente reativo dado pela constante necessidade de ajuste em face ao "tempo da produtividade" hegemônico. Tais ajustes, usualmente, fazem-se

1 Essa abordagem a partir do lugar foi aprofundada em Dozena (2011), na medida em que o samba paulistano foi abordado como um dado empírico do processo histórico, reconhecido em um comportamento cultural espacialmente definido. Relutantemente, em distintos locais e situações, ainda que o samba esteja sendo constantemente criado e recriado, mantém-se "vivo" e atuante na consciência de determinados agrupamentos sociais. Cabe frisar que o caráter desta visão é evidente naqueles sambistas que apresentam menor poder aquisitivo e se encontram mais "ligados" ao lugar. 
acompanhar pela coexistência de tempos e a superposição de realidades, envolvendo um confronto dialético constante entre a interioridade e a externalidade, entre o local e o global.

Essa difusão de um "tempo dos lentos" (concepção trabalhada por Milton Santos a partir da obra de Fernand Braudel) é também uma das principais respostas dos indivíduos à dinâmica da rapidez, da velocidade impetuosa, das manipulações dos meios de comunicação - que na fase histórica atual, geram um incrível complexo de imagens e abalos emocionais de episódios, tanto contínuos quanto transitórios. O movimento Slow Cities $^{2}$ parece caminhar no sentido de estabelecer um contraponto ao "motor social único" impulsionador da urbanização.

Por fim, é possível identificar na proposta de Milton Santos o tratamento do tempo e do espaço como indissociáveis. A essa "indissociabilidade" se agrega a noção de que o espaço geográfico não se trata apenas da materialidade (dos objetos), mas também envolve as ações humanas (o imaterial). Assim sendo, as ações humanas propiciam outros usos aos objetos geográficos (ao material), possibilitando uma miríade de apropriações criativas.

Vale ainda mencionar a contribuição feita pelo historiador inglês Edward Thompson (1998), ao buscar reconstruir a história a partir "de baixo", permitindo-nos refletir sobre as territorializações sob esse ponto de vista.

\section{O PAPEL DA CORPOREIDADE NA CONFORMAÇÃO DAS TERRITORIALIZAÇÕES URBANAS}

O artigo de Milton Santos (1996) "Por uma geografia cidadã: Por uma epistemologia da existência" nos é útil como ponto de partida; na medida em que tem o objetivo principal de apresentar as dimensões da corporeidade, da individualidade e da sociabilidade como importantes atributos para o estudo do cotidiano desde um ponto de vista espacial.

Em primeiro lugar, devemos destacar que a dimensão da corporeidade se revela enquanto oportunidade de criação de redes de convivência e de solidariedade, traduzindo-se como o núcleo primeiro da sociabilidade. Ela é um primeiro reconhecimento que se dá entre as pessoas, uma primeira forma de apresentação fundamental para a interação que acontece com outros corpos; no ato da socialização.

A própria corporeidade do pesquisador fica patente nos contatos que ocorrem nos trabalhos de campo, conforme observa o antropólogo Luiz Henrique de Toledo, ao afirmar que "a corporalidade é imprescindível na formulação das estratégias de distinção e fixação de estilos que modulam a sociabilidade jovem metropolitana, sendo o próprio corpo do pesquisador um veículo dessa inteligibilidade" (TOLEDO, 2007, p. 258).

2 Para maiores informações, consultar o conteúdo disponível em: <http://www.slowmovement.com/slow_cities.php>. Acesso em: 03 abr. 2011. 
A corporeidade torna-se fundamental para a conformação das estratégias de distinção e fixação de estilos demarcadores da sociabilidade, enunciando territórios precisos e modelos de indivíduos singulares: sambistas, músicos instrumentistas, jovens black, evangélicos, forrozeiros etc - que nas cidades, exercem apropriações particulares.

Por outro lado, o corpo traz as marcas da cultura em que está inserido, apontando caminhos para a compreensão de uma "performatividade" que parte do próprio corpo e envolve os movimentos realizados e influenciados pelas musicalidades presentes nos lugares. Deste modo, dá-se um diálogo com o lugar, que se apresenta no corpo, a partir de elementos do contexto socioespacial. Não é por acaso que dos diferentes modos de apropriação territorial criam-se subjetivações territoriais que se reproduzem nas músicas, nas melodias, nos ritmos, nas danças, nas letras e nas harmonias.

Admitida esta íntima vinculação entre o corpo e o contexto espacial, teremos que cada sociedade se expressa distintamente segundo os corpos e suas construções culturais diferenciadas. Assim, dentro de cada contexto espacial particular, as sociedades produzem suas manifestações culturais e delas são o resultado.

Isso não significa que o corpo não esteja geralmente disposto e apto a aprender novas técnicas ou métodos para realizar determinada prática corporal que envolva movimentos ou ritmos (a exemplo das aulas de danças brasileiras). De certa forma, há nesses casos um "descolamento" entre o corpo e o contexto espacial em que ele está inserido3.

Uma das questões que são relevantes para a reflexão aqui proposta é a de que, a partir da corporeidade, as coletividades recriam "territórios originais" que atendem não somente às suas aspirações de sobrevivência material, mas também à expressão das especificidades culturais que efetivamente as mobilizam e animam ${ }^{4}$.

Milton Santos (1996) afirma que há uma relação entre a corporalidade, a individualidade e a sociabilidade capaz de definir a cidadania. Essas três dimensões são efetivamente vivenciadas pelos que "sentem na pele e por causa da pele" os constrangimentos associados a preconceitos de ordem racial.

Portanto, há uma relação entre o corpo e o contexto espacial em que ele está inserido, no qual cada sociedade se expressa distintamente segundo os corpos e suas construções culturais diferenciadas.

Da mesma forma, dialogando com o pensamento de Merleau-Ponty (1999), podemos considerar que o corpo constrói processos de identificação entre o mundo pessoal e o mundo público e, na interação com o outro, reafirmam-se ou mesmo se descobrem alguns aspectos da própria identidade/identidades. Assim sendo, pelo próprio ato de dançar ou

3 Exemplarmente, refletindo-se sobre as pessoas que sambam, constatamos que embora muitas delas tenham "trejeitos" de sambistas, em seu corpo revela-se o samba enquanto "coisa", enquanto técnica de sambar apreendida, que não incorpora uma vivência cotidiana com os "territórios do samba". Vemos aí aflorar o corpo biomecânico muito presente na sociedade ocidental: um corpo marcado pela cisão entre a mente e a própria cultura do local.

4 Podemos, por exemplo, notar que uma roda de samba excede em significados a sua condição de prática de lazer e se territorializa na apropriação de bares, de ruas, de praças públicas, de barracões, de lajes, de centros culturais ou de áreas situadas embaixo de viadutos. A espontaneidade presente em uma roda de samba permite um contraponto ao artificialismo da realidade por intermédio de uma postura humana que atua como contrafinalidade. É nesse nível de resistência dada pelo uso territorial e mediada pela energia, pelo corpo, pelos sonhos, esperanças, prazeres e aspirações que os sentidos da existência humana podem se sublevar. 
tocar, o corpo articula uma linguagem que coloca os sujeitos em grupos territorialmente localizáveis, grupos que guardam relações ancestrais em que a experiência corporal fixa o território na existência, na medida em que o corpo é o ser no território.

Além da corporeidade, vale lembrar que muitos aspectos culturais advêm de heranças adquiridas de tempos passados, estando ainda hoje demarcados pelas relações de sociabilidade. É o que se pode perceber quando o corpo reage diante de certos códigos, símbolos e imaginários, diante do "ethos", do conjunto dos costumes e hábitos fundamentais verificados no âmbito dos comportamentos sociais (instituições, afazeres) e da cultura (valores, ideias ou crenças) característicos de uma determinada coletividade, época ou região ${ }^{5}$.

Para Milton Santos (2002), a globalização possibilita a redescoberta da corporeidade, dimensão que se revela enquanto oportunidade de criação de redes de convivência e de solidariedade. Nesse sentido, é interessante notar que, no caso brasileiro, a corporeidade geralmente vem acompanhada de estereótipos criados nas relações sociais: a existência de um paulistano típico, de um carioca típico, de um baiano típico ou de um cearense típico, por exemplo. Tais estereótipos, fundamentados principalmente nos trejeitos e no modo de falar, acabam contribuindo para a continuidade do embate regional e da intolerância.

Ao contrário dessa não aceitação dos territórios específicos presentes nos corpos, o estranhamento pode ser superado mediante a assimilação e a inserção dos diferentes conjuntos de códigos e de símbolos culturais no conjunto da sociedade. Do mesmo modo, conforme nos indicam algumas situações cotidianas, a aparência diferenciada de cada indivíduo leva à existência de uma marca social para cada corpo, o que influencia até onde determinado corpo pode ir ou circular, também influenciando a conformação das territorializações. Por outro lado, a própria materialidade gera condicionamentos para que certas territorializações não aconteçam.

A esse respeito, no filme "Encontro com Milton Santos ou o Mundo Global visto do lado de cá", há uma cena na qual os moradores de uma favela vão passear em um movimentado Shopping-Center da zona sul carioca. Nesse momento, torna-se perceptível que a objetividade da corporeidade desses moradores infringe um território que inicialmente não previa o uso por essa população. O encontro inesperado entre os frequentadores do shopping e os moradores da favela provoca surpresa, sendo que os últimos descobrem uma nova realidade ao passo em que observam e são observados. No outro mundo possível, defendido por Milton Santos em seus escritos e exposições orais, aquela situação deveria acontecer, ou seja, a de todos poderem ir e vir livremente ${ }^{6}$.

5 Considerando-se ainda o caso do samba, o território congrega esta herança de tempos diferentes que está presente no corpo dos sambistas, em seus costumes e práticas, que passam a ser socializados comumente pelos sons reconhecidos por todos. Assim, observamos que muitas afinidades são criadas através dessa base territorial, que são definidoras de uma importante dimensão relacional que se dá a partir da subjetivação com os territórios (que aqui também se configuram geograficamente em lugares).

6 Observação a mim feita por Samarone Marinho. 
Podemos ampliar a reflexão se consideramos que a temática da corporeidade está diretamente associada com a temática da musicalidade, que por sua vez, relaciona-se com a riqueza de sons provenientes dos cantos, dos rituais religiosos e da dança. Desse modo, a musicalidade pode ser vista como um álibi para se atingir alguns fatos geográficos, sobretudo ao constatarmos que as letras e as sonoridades trazem consigo uma historicidade que usa metáforas importantes para a desconstrução de conceitos e pré-conceitos socialmente estabelecidos.

Essa musicalidade pode ser trazida ancestralmente pelas coletividades, atendendo não somente às vontades de reprodução material e às necessidades de sobrevivência, mas também expressando muitas especificidades culturais que efetivamente mobilizam e animam os agrupamentos sociais, ao mesmo tempo em que revelam uma história não oficial que passa a ser contada pelas ruas e bairros das cidades brasileiras.

As músicas contribuem para a criação de uma ligação emotiva e humana com os lugares, além de demarcarem corporeidades, territorializações e relações socioespaciais, sendo produzidas a partir de estímulos colocados pelos lugares e por isso mesmo evidenciando o sentido desses lugares.

Por sua vez, as identidades com base territorial, forjadas por aspectos da musicalidade, trazem conexões com padrões passados e presentes de povoamento, migrações, etnicidades, heranças musicais, estilos de vida e condições socioeconômicas. A grande questão é a de se atentar para o fato de que além de um corpo fisiológico existe um corpo social, criador de uma musicalidade que se verifica na existência individual e coletiva. Há muitas evidências de que algumas habilidades sensóreo-motoras dos sujeitos são ativadas nesta construção de identidades de base territorial. Um exemplo claro, no âmbito musical, é a própria estrutura rítmica e melódica que emerge como uma construção do processo de representação social, uma representação estabelecida cultural, ideológica e tecnicamente. Com clareza, existem características de lugares específicos que oferecem pré-condições às novas ideias musicais. Até mesmo alguns instrumentos musicais são criados conforme as condições propiciadas pelos lugares, condições retomadas e reverberadas a partir do repertório cultural próprio de cada agrupamento social7.

Contrariando muito do que é propagado pela dita "cultura oficial", algumas pessoas tidas como "simples" trazem consigo sua cultura musical ainda não massificada (embora recebam fortes influências que tendem a desestabilizá-la), mas demarcada por profundos laços psicológicos e emocionais com os lugares por elas vivenciados.

Aqui, novamente, o tema da musicalidade permite que pensemos em sistemas de percepção, de estéticas e de cantos interpretativos próprios. Muito dessas "culturas não oficiais" são "invisíveis" para grande parte da sociedade brasileira, sendo tratadas como

7 Ilustrativamente, a musicalidade do samba favorece a espontaneidade e a sociabilidade de diversas maneiras, uma vez que os instrumentos do samba podem estimular o improviso. Com quase tudo se faz samba, da caixinha de fósforo, nasce um chocalho, bem como de uma latinha ou garrafa vazia; de uma tampa ou prato, surge um reco-reco, de um balde, cria-se um tambor e, apesar dessa musicalidade ser complexa, pois requer um grande entrosamento para que o ritmo se expresse harmonicamente com todos os instrumentos e sons, sua produção pode ser simples, excitando o convívio pelo olhar e pelos sons. A roda de samba requer cumplicidade e quem não toca, dança, quem não dança, canta, quem não canta, assiste. Eis possivelmente uma das razões pelo qual o samba seja gregário, facilitando as demarcações de território e de agrupamentos sociais. 
manifestações culturais subalternas, em que os sujeitos são transformados em objetos ainda que estabeleçam relevantes territorializações urbanas enquanto práticas de resistência.

\section{CONSIDERAÇÕES FINAIS}

É interessante salientar que até algumas décadas atrás, o presente era muito assinalado pelas ações das sociedades anteriores, enquanto presentemente, a ação mais vigorosa é aquela oriunda da sociedade contemporânea. Sobre isso, Milton Santos (2002) considera que não é mais o passado que nos guia, mas o futuro imediato, o projeto e as interações possíveis.

Este parece mesmo ser um importante ensinamento: o de que a memória é um aglutinante social e as horizontalidades, o alicerce do futuro, pois: "enquanto a memória é coletiva, o esquecimento e a consequente (re)descoberta são individuais, diferenciados, enriquecendo as relações interpessoais, a ação comunicativa. Assim, o que pareceria uma inferioridade é, na realidade, uma vantagem" (SANTOS, 2002, p. 330).

E o futuro pode ser vislumbrado pelos vínculos intensos e as interações que se dão entre homens e mulheres, ao perceberem que a cooperação envolve o acontecer nas horizontalidades e atua como uma contrafinalidade que nem sempre faz parte de um sistema de objetivos claros e materiais, mas pode ser gratuito, desinteressado, espontâneo e desprovido de objetivos. Em suas práticas, os indivíduos podem passar à distância da finalidade, da objetivação, sendo apenas seres humanos que vivenciam a amizade, a presença gratuita e a capacidade de congregação que se dá mediada pelas territorializações e pela corporeidade. Os agrupamentos sociais nem sempre "objetivam" o tempo, mas podem simplesmente conviver coletivamente e reinventar a sua realidade, isentos de obrigações.

Finalizamos com Sartre (2002), que considera que um ato mediado pela imaginação é prenhe de intencionalidades na medida em que cada ser consciente elabora, numa relação entre o corpo e o pensamento, a ação poiética que principia a sua participação no mundo humano. Ainda no sentido sartriano, a esperança existe como parte da ação, estabelecendo um jogo dialético entre a "cidade do modo ter de existência" e a "cidade do modo ser de existência".

\section{REFERÊNCIAS}

ADORNO, Theodor. Indústria cultural e sociedade. Seleção de textos por Jorge Mattos Brito de Almeida. 5. ed. São Paulo: Paz e Terra, 2002.

BORDIEU, Pierre. A economia das trocas simbólicas. São Paulo: Perspectiva, 1987.

DOZENA, Alessandro. A geografia do samba na cidade de São Paulo. 1. ed. São Paulo: Fundação PoliSaber, 2011.

FOUCAULT, Michel. Microfísica do poder. Rio de Janeiro: Graal, 1979. 
GOMES, Paulo César da Costa. A condição urbana: ensaios de geopolítica da cidade. Rio de Janeiro: Bertrand Brasil, 2002.

HAESBAERT, Rogério. Territórios alternativos. São Paulo: Contexto, 2006.

LA BLACHE, Vidal de. Princípios de geografia humana. Lisboa: Cosmos, 1954.

LEFEBVRE, Henry. A vida cotidiana no mundo moderno. São Paulo: Ática, 1991.

MARX, Karl. O capital. São Paulo: Abril Cultural, 1983. (Os Pensadores).

MERLEAU-PONTY, Maurice. Fenomenologia da percepção. São Paulo: Martins Fontes, 1999.

SARTRE, Jean Paul. Crítica da razão dialética: precedido por questões de método. DP\&A, Rio de Janeiro, 2002.

SANTOS, Milton. A natureza do espaço: técnica e tempo, razão e emoção. São Paulo: EDUSP, 2002. Coleção Milton Santos.

Por uma outra globalização: do pensamento único à consciência universal. 15. ed. São Paulo: Record, 2008.

. Por uma geografia cidadã: por uma epistemologia da existência. Boletim Gaúcho de Geografia, Porto Alegre, n. 21, ago. 1996.

THOMPSON, Edward P. Costumes em comum. Estudos sobre a cultura popular tradicional. São Paulo: Companhia das Letras, 1998.

TOLEDO, Luiz Henrique de. Corporalidade e Festa na Metrópole. In: MAGNANI, José Guilherme Cantor; SOUZA, Bruna M. de Souza. Jovens na Metrópole. Etnografias de circuitos de lazer, encontro e sociabilidade. São Paulo: Terceiro Nome, 2007. p. 255-266.

WILLIANS, Raymond. Marxismo y literatura. Barcelona: Editorial Península, 1980.

Recebido em 14/01/2012

Aceito para publicação em 22/03/2012 